\title{
Assessing the Effect of Oral Versus Intravenous Fluids on Progress of Labor and Fetal Outcomes
}

\author{
Shaimaa Hassan Mohamady*, Hanan Fawzy Elsayed Ali \\ Maternal \& Newborn Health Nursing Department, Faculty of Nursing, Helwan University, Helwan, Egypt \\ Email address: \\ dr_shaimaamohamady@yahoo.com (S. H. Mohamady), HananFawzy78@yahoo.com (H. F. E. Ali) \\ ${ }^{*}$ Corresponding author
}

To cite this article:

Shaimaa Hassan Mohamady, Hanan Fawzy Elsayed Ali. Assessing the Effect of Oral Versus Intravenous Fluids on Progress of Labor and Fetal Outcomes. American Journal of Nursing Science. Vol. 6, No. 1, 2017, pp. 19-25. doi: 10.11648/j.ajns.20170601.13

Received: December 10, 2016; Accepted: December 24, 2016; Published: January 19, 2017

\begin{abstract}
Background: Childbirth is a natural physiological process, yet it is a life -changing events for many women. However, the care given to women during labor has the potential to affect them both physically and emotionally, likewise, short and long term labor and delivery management are the most common medical issues facing the health caregivers. The study aimed to evaluate effects of oral versus intravenous hydrations on progress of labor and fetal outcomes. A, quasiexperimental design was utilized. Purposive samples of 112 parturient women were randomly allocated into the study and the control groups. The study was conducted at obstetric and gynecologic department, Helwan General Hospital, Egypt. Data were collected through four main tools: structured interviewing questionnaire, delivery and maternal assessment, the Partograph, and neonatal assessment record. The study findings indicated that no significant differences were found between the two groups in their demographics, the mean duration of the first stage of labor in study group was significantly shorter than the control group. However, the duration of the second stage and the third stage of labor in the study group were significantly shorter than the control group. There were statistical significant difference among the study group and control group regarding the two Apgar scores in $1^{\text {st }}$ and $5^{\text {th }}$ minutes. The study and research hypothesis concluded that administration of intravenous infusion enhances labour and reduce the first stage of labour duration, consequently, the duration of labour. The study recommended the benefit of increased intravenous hydration in labor, as well as the role of supplemental oral hydration.
\end{abstract}

Keywords: Birth Outcome, Duration of Labor, Intravenous Fluids

\section{Introduction}

Birth is a life changing event and the care given to women has the potential to affect them both physically and emotionally in the short and longer term. The overall objective taking care of women during childbirth is creating a positive experience for a woman and her family while preserving their physical and psychological health, preventing of morbidity and reaction to the emergency situations. [1] Factors that affect the progress of labor have been studied extensively in an effort both to increase our understanding of normal labor and improve our ability to treat abnormal labor so that labor progress can be enhanced and operative deliveries avoided. Labor is exactly as its name implies hard, physical work. When we work hard, we need to remain adequately hydrated. Drinking to thirst is often an appropriate way to ensure we remain hydrated during activities. [2] Inadequate hydration in labor may be a factor contributing to dysfunctional labor and possibly of cesarean delivery. Adequate fluid would be important for optimal uterine perfusion, required not only for fetal oxygenation but also for delivery of nutrients and elimination of waste from the contracting myometrium. In most labor units, oral liquid is restricted because of concern over aspiration if an unanticipated general anesthetic is required [3].

Adequate fluid administration may improve labor. Fluid is usually administered at a rate of $125 \mathrm{ml}$ per hour intravenously as routine during labor, this regimen is used for resting patients not taking oral fluids and many women 
become clinically dehydrated during labor with this regimen. Increased need for hydration during labor can result in a decreased intravascular volume if fluid replacement is not adequate. Because uterine blood flow is not auto regulated, a decrease in blood volume would result in a decrease in uterine blood flow. [4] Labor may be considered to be a period of prolonged exercise. Laboring women may become dehydrated as a result of the physical exertion caused by the muscles of the womb contracting. In many institutions women are subjected to a questionable policy of restricted oral intake. Only sips of water or ice chips are allowed. In institutions where this is employed, women are given routine intravenous fluids through a "drip". [5] Sports medicine literature indicates that adequate hydration is useful for peak athletic performance. Labor and birth can be viewed as a physical endurance event. It is logical; therefore, that adequate hydration contributes to an effective labor. Indeed, well-known midwifery educator states. The maintenance of hydration throughout labor is essential for the woman's well-being. Optimal hydration for labor has never been defined, and little research exists to guide provider choice in this area. [6] The actual amount of hydration that a laboring uterus requires for efficient contraction, has not been quantified. It does seem logical that adequate hydration and perhaps supplemental glucose is required to maintain endurance and muscle efficiency during the process of labor and parturition, but is the routine administration of intravenous fluids entirely necessary. [7] Nurses play a major role in preparing the patient for administering IV infusion and monitoring mother and fetus during the labor process. Because the choice of IV fluid, its form of administration and its side effects varies, knowledge of uterine physiology is an important aspect of caring for women and their fetus undergoing treatment with these fluids. [8] Child birth is a highly emotional event that engenders anxiety and apprehension for the mother such feelings can be enhanced by supportive companions. The nurse has to ensure that all laboring women receive support, not only from those close to them, but also from experienced care givers. Forms of support that should be routinely offered to women include; continuous presence with the mother, keeping the mother informed about the purpose of every procedure and the results of each examination. [9] Lastly the prenatal nurse is in continuous attendance at the bedside until delivery achieved, assess maternal and fetal responses to the infusion rate to evaluate the progress of labor and to monitor intake and output. Therefore, obstetric nurses should exert efforts to upgrade their knowledge and practice required in the care of women undergoing labor. [10]

\subsection{Significance of the Study}

Intravenous fluids administration that can bring about significant improvements in maternal and fetal well-being In addition, during the clinical experience, the researchers observed that the use of routine intravenous fluids administration during labour that have positive effect on progress of labour and prevalent without a forceful body of evidence. Furthermore, little studies have been noted regarding the safety and efficacy of routine intravenous fluids, and the potential dangers of some types of fluids. The main aim of this study is to determine the effect of the routine intravenous fluid administration on the duration of labor.

\subsection{Aim}

This study aimed to evaluate effects of oral versus intravenous hydrations on progress of labor and fetal outcomes. This aim was achieved through:

- Assessing effect of receiving early or routine intravenous fluid on the duration and course of labor.

- Determining the risks and benefits of early or routine intravenous fluid administration during labor.

- To determine the risks and benefits of different fluid regimens (ie. different volumes or different types of fluids and or both) used in labour.

\subsection{Study Hypothesis}

Parturient women encouraged to receive intravenous fluids will have a positive effect on birth outcomes (maternal and neonatal) than do not instructed to receive Intravenous Fluids.

\section{Subjects and Methods}

\subsection{Study Design}

A quasi-experimental design was utilized to fulfill the aim of this study.

\subsection{Study Setting}

This study was conducted in the labor ward, affiliated at obstetric and gynecologic department, Helwan General Hospital, Egypt.

\subsection{Subjects}

A purposive sample of 112 parturient women was recruited for the study and fulfilled the following inclusion criteria; age 25-35 years old, at 37 and 42 weeks of gestation, multigravida (parity, $\leq 5$ ), were anticipating a vaginal birth, with a healthy single vertex fetus, absence of intrapartum complications, and willing to participate in the study. Exclusion criteria; women with co-existing medical or obstetrical risk factors, malpresentation, postdate pregnancy and abnormal fetal heart rate during the first stage.

Sample size and technique. According to the Helwan hospital statistical center (2012): [11] flow rate of normal vaginal delivery for parturient women was 1021 women at the end of year 2014. Ten percent of flow rate (102 women) was selected. Considering dropout during follow-up, the researcher added 10\%. Thus the sample size was 112 parturient women, the sample was randomly allocated in two equal groups, study group (56) and control group (56). 


\subsection{Study Tools}

Four main tools were used for data collection.

Tool I- A structured interviewing questionnaire: this was developed by the researcher in the Arabic language. It consisted of two parts,

1. The first part concerned with general characteristics data of the studied sample such as, age, residence, level of education, occupation.

2. The second part was concerned with obstetric data included parity, gravidity, gestational weeks.

Tool II-Delivery and maternal assessment sheet

This included duration of labor, mode of delivery, and labor complications such as postpartum hemorrhage, episiotomy, or perineal lacerations.

Tool III: "The Partograph" This tool was adapted and used by [12] WHO, to measure the progress of labor in term of cervical dilatation, effacement, descent of the fetal head, uterine contraction progress (duration, frequency, interval and intensity) fetal heart rate, duration of first, second and third stage of labor

Cardiotocography (CTG) was used to monitor the fetal heart count, and uterine contraction (frequency, and intensity).

Tool IV-Neonatal assessment record

This included Apgar scores in the first and fifth minute adopted from Apgar score, birth weight, need for admission to the neonatal intensive care unit. [13]

Validity of the tools: Content validity was done through five experts in field of maternal health nursing and obstetrics medicine Specialty to ascertain relevance and completeness.

Reliability of the tools: Reliability coefficients were calculated for questionnaire items. The coefficient alpha was $76.00 \%$.

\subsection{Pilot Study}

A pilot study was carried out with $10 \%$ of the total number of sample (11 women) to assess the tools clarity, objectivity and feasibility. As well to estimate the time needed for data collection. Women in the pilot study were included in the main study sample since no modifications were done.

\subsection{Ethical Considerations}

The purpose of the study was explained to each woman and a written consent was obtained from each of those who agreed to participate. They were assured about confidentiality and privacy and that this information will be used only for research purposes only and each woman in both groups was informed of the rights to refuse or withdraw at any time.

\subsection{Procedure}

After formal permission from the director of Helwan hospital was obtained. The researcher visited the pre mentioned setting three days/week during the morning or afternoon shift according the circumstance of the researcher and approached all women who met the inclusion criteria during the research period that started from the beginning of June, 2015 to the end of November, 2015. Women who met the study criteria were clearly briefed on research purposes, intervention benefits, risks, and procedure, an oral consent was taken.

\subsection{Field Work}

All women have undergone through history taking personal, obstetric, present, and past history including drug history and family history. After that, general and local examinations were done. All women subjected to the following investigations (complete blood culture, complete urine analysis, blood sugar testing and Rh group). Each woman was randomly allocated into two groups the first group includes 56 pregnant women and this group will receive $250 \mathrm{ml}$ per hour of glucose solution intravenously (Study group). The second group Includes 56 pregnant women who received oral fluids only (control group). The rate of infusion was determined by infusion pump. No drugs used intrapartum except analgesia by $50-100 \mathrm{mg}$ pethidine IM. All women were put on the partogram to assess the progress of labour in the two groups. For all women the following was recorded on the partogram (FHR, membrane status and liquor, moulding of the skull, presence of caput, cervical dilatation and effacement, descent of the head, uterine contractions, maternal pulse, maternal blood pressure, maternal temperature and drugs given with its rate and dose). Oral fluid included water, and juice or carbonated soft drinks. Fluids were graduated in at one liter container. Amniotomy and oxytocin administration were allowed according to the physician's discretion. The rate was measured with an infusion pump in women randomized to the intravenous group. Amniotomy, analgesia and oxytocin administration were allowed according to the physician's discretion. All the outcomes were recorded by a researcher. The primary endpoints looked at were, total duration of active labor, mode of delivery, incidence of caesarean section for failure to progress and Neonatal ICU admission and serious maternal complications. During follow-up a satisfactory progress was identified as cervical dilatation of $1 \mathrm{~cm}$ or more per hour. If the progress was unsatisfactory labor was augmented using oxytocin infusion until regular uterine contraction was established.

\subsection{Statistical Design}

Data were verified prior to computerized entry. The Statistical Package for Social Sciences (SPSS version 20.0) was used. Descriptive statistics were applied (e.g., mean, standard deviation, frequency and percentages). Tests of significance (chi square, Fisher exact test and independent $t$ test) were used to test the study hypothesis. 


\section{Results}

Table 1. Distribution of the studied women according to their demographic and obstetric characteristics $(n=112)$.

\begin{tabular}{|c|c|c|c|c|c|c|c|}
\hline \multirow[b]{2}{*}{ Characteristi } & \multirow[t]{2}{*}{ Group } & \multicolumn{2}{|c|}{ Study group $n=56$} & \multicolumn{2}{|c|}{ Control group $n=56$} & \multirow{2}{*}{$X^{2}$} & \multirow{2}{*}{ p value } \\
\hline & & No & $\%$ & No & $\%$ & & \\
\hline \multicolumn{8}{|l|}{ Age (years) } \\
\hline $20<25$ & & 26 & 46.4 & 23 & 41.0 & & \\
\hline $25<30$ & & 28 & 50.5 & 30 & 53.6 & Fisher exact test & $0.614^{\mathrm{ns}}$ \\
\hline $30 \leq 35$ & & 2 & 3.6 & 3 & 5.4 & & \\
\hline $\begin{array}{l}\text { Mean } \pm \text { SD } \\
\text { Residence }\end{array}$ & & \multicolumn{2}{|c|}{$29.94 \pm 2.65$} & \multicolumn{2}{|c|}{$28.73 \pm 3.61$} & $\mathrm{t}=0.644$ & $0.521^{\mathrm{ns}}$ \\
\hline Urban & & 19 & 33.9 & 17 & 30.4 & 0.164 & $0.686^{\mathrm{ns}}$ \\
\hline Rural & & 37 & 66.1 & 39 & 69.6 & & \\
\hline Educational level & & & & & & & \\
\hline Primary & & 16 & 28.6 & 18 & 32.1 & & \\
\hline Secondary & & 27 & 48.2 & 23 & 41.1 & 0.581 & $0.748^{\mathrm{ns}}$ \\
\hline High & & 13 & 23.2 & 15 & 26.8 & & \\
\hline Occupation & & & & & & & \\
\hline Working & & 27 & 48.2 & 25 & 44.6 & 0.144 & $0.705^{\mathrm{ns}}$ \\
\hline Housewife & & 29 & 51.8 & 31 & 55.4 & & \\
\hline
\end{tabular}

Independent $\mathrm{t}$ test ${ }^{\mathrm{ns}}$ not significant at $\mathrm{p} \geq 0.05$.

Table 1 shows socio demographic characteristics of the studied sample. It was clear that $50.0 \%$ and $53.6 \%$ of study and control groups respectively were in the age group $25<$ 30 years with a mean age of $29.94 \pm 2.65$ years and $28.73 \pm$ 3.61 years respectively. Regarding residence, about two thirds of the study group $66.1 \%$ and control group $69.6 \%$ were living in rural areas. Less than half of the study group and control group $48.2 \%$ and $41.1 \%$ respectively were had secondary education. More than half of both group were housewives. There was no statistically significant difference between study group and control group regarding socio demographic characteristics and gestational age.

Table 2. Distribution of the studied women regarding to their reproductive history ( $n=112)$.

\begin{tabular}{|c|c|c|c|c|c|c|c|}
\hline \multirow[b]{2}{*}{ Reproductive history } & \multirow[t]{2}{*}{ Group } & \multicolumn{2}{|c|}{ Study group $n=56$} & \multicolumn{2}{|c|}{ Control group $n=56$} & \multirow{2}{*}{$\mathrm{X}^{2}$} & \multirow[b]{2}{*}{$p$ value } \\
\hline & & No & $\%$ & No & $\%$ & & \\
\hline \multicolumn{8}{|l|}{ Gravidity } \\
\hline Gravida (2) & & 28 & 50.0 & 27 & 48.2 & \multirow[t]{4}{*}{0.510} & \multirow[t]{3}{*}{$>0.05^{\text {ns }}$} \\
\hline Gravida (3) & & 17 & 30.4 & 16 & 28.3 & & \\
\hline Gravida (4) & & 11 & 19.6 & 13 & 23.5 & & \\
\hline \multicolumn{7}{|l|}{ Parity } & \\
\hline Para(1) & & 28 & 50.0 & 27 & 48.2 & \multirow{3}{*}{0.83} & \multirow{3}{*}{$>0.05^{\mathrm{ns}}$} \\
\hline Para(2) & & 18 & 32.1 & 19 & 33.9 & & \\
\hline Para(3) & & 10 & 17.9 & 10 & 17.9 & & \\
\hline \multicolumn{8}{|l|}{ Gestation (weeks) } \\
\hline Mean (SD & & \multicolumn{2}{|c|}{$39.62 \pm 1.32$} & \multicolumn{2}{|c|}{$39.66 \pm 5.86$} & $\mathrm{t}=0.246$ & $0.806^{\mathrm{ns}}$ \\
\hline
\end{tabular}

Independent $\mathrm{t}$ test ${ }^{\mathrm{ns}}$ not significant at $\mathrm{p} \geq 0.05$

Table 2. also reveals no statistically significant differences between the study and the control groups concerning reproductive history; gravidity, parity, and gestational age $\mathrm{p}<0.05$.

Difference between two groups in duration of the first stageof labour

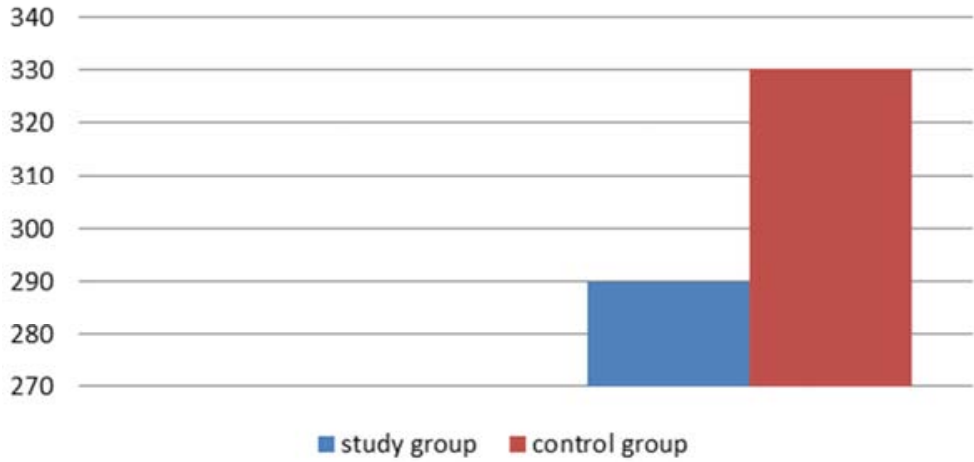

Figure 1. Difference between two groups in duration of the first stage of labor. 
Figure 1. Showed women in study group had a shorter first stage of labor than and control group this difference was statistically significant $292.50 \pm 50.47 \mathrm{~min}$. and $329.56 \pm 43.28 \mathrm{~min}$ respectively.

Table 3. Comparison between the studied women in both groups according to maternal outcome ( $n=112)$.

\begin{tabular}{|c|c|c|c|c|c|c|}
\hline \multirow{2}{*}{ Maternal outcome $\quad$ Group } & \multirow{2}{*}{\multicolumn{2}{|c|}{$\begin{array}{l}\text { study group } n=56 \\
\text { Mean } \pm \text { SD }\end{array}$}} & \multicolumn{2}{|c|}{ control group $n=56$} & \multirow{2}{*}{ independent $\mathrm{t}$ test } & \multirow{2}{*}{ p value } \\
\hline & & & \multicolumn{2}{|c|}{ Mean \pm SD } & & \\
\hline Duration of second stage (minutes) & \multicolumn{2}{|c|}{$33.16 \pm 2.86$} & \multicolumn{2}{|c|}{$48.07 \pm 4.22$} & 21.904 & $0.000 * *$ \\
\hline Duration of third stage (minutes) & \multicolumn{2}{|c|}{$9.57 \pm 0.89$} & \multicolumn{2}{|c|}{$13.69 \pm 1.63$} & 16.628 & $0.000 * *$ \\
\hline Variable & No & $\%$ & No & $\%$ & Test of significance & $\mathrm{p}$ value \\
\hline \multicolumn{7}{|l|}{ Mode of delivery } \\
\hline Normal Vaginal Delivery & 55 & 98.2 & 45 & 82 & \multirow[t]{2}{*}{ Fisher exact test } & \multirow[t]{2}{*}{$0.000 * *$} \\
\hline Cesarean Section & 1 & 1.8 & 11 & 12 & & \\
\hline None & 54 & 96.4 & 48 & 85.7 & \multirow{4}{*}{ Fisher exact test } & \multirow{4}{*}{$0.226^{\mathrm{ns}}$} \\
\hline First degree & 1 & 1.8 & 5 & 8.9 & & \\
\hline Second degree & 1 & 1.8 & 2 & 3.6 & & \\
\hline Third degree & 0 & 0.0 & 1 & 1.8 & & \\
\hline \multicolumn{7}{|l|}{ Maternal complications } \\
\hline Yes & 0 & 0.0 & 2 & 3.6 & \multirow[t]{2}{*}{ Fisher exact test } & \multirow[t]{2}{*}{$0.154^{\mathrm{ns}}$} \\
\hline No & 56 & 100.0 & 54 & 96.4 & & \\
\hline
\end{tabular}

${ }^{\mathrm{ns}}$ not significant difference at $\mathrm{p} \geq 0.05$.

** A highly significant difference at $\mathrm{p} \leq 0.001$.

* Significant difference at $\mathrm{p} \leq 0.05$.

Table 3. Represent the maternal birth outcome of the studied women in both groups. Regarding the duration of the second stage and the third stage of labor in the study group were significantly shorter than the control group $p \leq 0.001$. The mean duration of the second stage and the third stage of labor in the study group were $33.16 \pm 2.86$ minutes and 9.57 \pm 0.89 minutes respectively compared to in the control group $48.07 \pm 4.22$ minutes and $13.69 \pm 1.63$ minutes meanwhile, there was no statistically significant difference between both groups regarding mode of delivery, perineal lacerations, and maternal complications.

Table 4. Characteristics of newborns in the both studied groups $(n=112)$.

\begin{tabular}{|c|c|c|c|c|c|c|}
\hline \multirow[b]{2}{*}{ Neonatal outcome } & \multicolumn{2}{|c|}{ study group $n=56$} & \multicolumn{2}{|c|}{ control group $n=56$} & \multirow{2}{*}{ independent $\mathrm{t}$ test } & \multirow{2}{*}{ p value } \\
\hline & \multicolumn{2}{|c|}{ Mean \pm SD } & \multicolumn{2}{|c|}{ Mean \pm SD } & & \\
\hline Birth weight (gm) & \multicolumn{2}{|c|}{$3243.93 \pm 82.92$} & \multicolumn{2}{|c|}{$3248.43 \pm 98.83$} & 0.261 & $.795^{\mathrm{ns}} 0$ \\
\hline Head circumference $(\mathrm{cm})$ & \multicolumn{2}{|c|}{$33.71 \pm 0.98$} & \multicolumn{2}{|c|}{$33.64 \pm 1.14$} & .3560 & $.723^{\text {ns }} 0$ \\
\hline Apgar score (1 minute) & \multicolumn{2}{|c|}{$8.14 \pm 0.67$} & \multicolumn{2}{|c|}{$7.57 \pm 0.49$} & 5.106 & $.000 * * 0$ \\
\hline Apgar score (5 minute) & \multicolumn{2}{|c|}{$9.54 \pm 0.50$} & \multicolumn{2}{|c|}{$9.23 \pm 0.79$} & 2.434 & $.017 * 0$ \\
\hline Variable & No & $\%$ & No & $\%$ & Test of significance & $\mathrm{p}$ value \\
\hline \multicolumn{7}{|l|}{ Need to resuscitation } \\
\hline No & 56 & 100.0 & 54 & 96.4 & $\begin{array}{l}\text { Fisher exact } \\
\text { test }\end{array}$ & $0.154^{\mathrm{ns}}$ \\
\hline \multicolumn{7}{|l|}{ Admission to neonatal intensive care unit } \\
\hline Yes & 0 & 0.0 & 1 & 1.8 & \multirow{2}{*}{$\begin{array}{l}\text { Fisher exact } \\
\text { test }\end{array}$} & \multirow[t]{2}{*}{$0.315^{\mathrm{ns}}$} \\
\hline No & 56 & 100.0 & 55 & 98.2 & & \\
\hline
\end{tabular}

${ }^{\mathrm{n} s}$ not significant difference at $\mathrm{p} \geq 0.05$.

** A highly significant difference at $\mathrm{p} \leq 0.001$.

* Significant difference at $\mathrm{p} \leq 0.05$.

Table 4. clarifies neonatal birth outcome, there was no significant differences in birth weight, head circumference, neonatal complications as the need for resuscitation and admission to the neonatal intensive care unit were observed between the groups $p>0.05$. However, the newborn of study group had significantly higher Apgar scores in $1^{\text {st }}$ and $5^{\text {th }}$ minutes than the newborn of control group $p<0.001$ and $\mathrm{p}<0.05$ respectively. The mean of $1^{\text {st }}$ minute Apgar score for the study group and control group was $8.14 \pm 0.67$ and $7.57 \pm$ 0.49 respectively; while mean the $5^{\text {th }}$ minute of the Apgar score for study group and control group groups was $9.54 \pm$ 0.50 and $9.23 \pm 0.79$ respectively.

\section{Discussion}

Childbirth is a dramatic situation where a new life is created. However, enormous amounts of physical and psychological energy are consumed during parturition and adaptation to the new role as a mother [7]. This study aimed to evaluate effects of oral versus intravenous hydrations on progress of labor and fetal outcomes. The findings of the current study showed no statistically significant difference between both the study and control groups were matching in almost all aspects of their demographic characters and reproductive history. This finding is in agreement with Kavitha et al, 2012 [14] who emphasized 
that the women in the study were no significant differences between the study group and the control group for age, education level, and gestational age.

Concerning parity, the present study showed that, one half of women in the both group was Para. This finding means that the researchers selected the participant in the two groups by the same criteria. Similar findings were also reported by E slamian et al., (2011) [15] in united state of America. Regarding maternal outcome, the findings of the current study showed that the duration of first stage of labor, However, the same mean duration therefore the difference was not statistically significant the mean duration of the second stage of labor were statistically shorter by an average of 15 minutes and 4 minutes respectively in the study group versus the control group. These findings disagree with Rezk et al, (2010) [10] who found the duration of active phase as significantly shorter in the study group than in the control group, but there was no significant difference in the duration of the second stage between the three groups. An important outcome of the present study was the overall duration of labor interval which was shorter (mean hours) in the study group compared to (mean hours) in the conservative group with statistical significant difference. Direkvand M, 2012 [16] reported that the duration of the 2 nd and the 3 rd stages of labor were reduced for women receiving intravenous fluids, although the difference between groups for the third stage was not statistically significant. In relation to mode of delivery, the current study showed that, the number and percentage of women who delivered normally were more in the study group than that in the control group. The majority of women in the study group had normal vaginal delivery (98.2) compared to more than three quarters of women (82 \%) in the control group and the difference was statistically significant. These findings are in accordance with, GARITE, et al., 2000 [17] who found that, inadequate hydration in labor may be a factor contributing to dysfunctional labor and possibly cesarean delivery. This result disagrees with that of Kavitha, (2012) [14] who reported that, there was no statistically significant reduction in the number of caesarean sections (CS) in the intravenous fluid group (risk ratio (RR) $0.73,95 \%$ CI 0.49 to 1.08 ,) in the two studies (315 women). On the other hand, there was no statistically significant difference between both groups regarding perineal lacerations, and maternal complications. The present study examined the effect of the two lines of management on the neonatal outcome. Regarding to Apgar score, the current findings showed that fewer newborns had Apgar score in 1 st and 5th less than 7 at 5 minutes in the study group $8.14 \pm 0.67$ and $7.57 \pm 0.49$ respectively compared to ( $9.54 \pm 0.50$ and $9.23 \pm 0.79$ respectively) in the control group with statistical significant difference. More over the present study showed that, there was no strong evidence that the rate of infusion affected admission to NICU in the two studies babies, over all the number of admissions was relatively low with any statistically significant difference between both groups. These findings agree with Coco, (2010). [18]

\section{Conclusions}

Based on the findings of the present study it could be concluded that; Administration of intravenous infusion enhances labor and associated with shorter first stage of labour, consequently, the duration of labour, and improved newborn outcome. Therefore, the above mentioned findings proved and supported the research hypotheses.

\section{Recommendations}

In the light the current study findings, the following recommendations can be suggested:

- Intravenous hydrations could be a factor contributing to dysfunctional labor and possibly cesarean delivery.

- Simplified guidelines containing information about different stages of labor, the effect of intravenous hydrations on improve labor and fetal outcome should be available and displayed in the labor wards.

- Health pamphlets may also be produced to the pregnant women to improve awareness on the intravenous hydrations during labor.

\section{Further Studies}

Future studies may wish to reevaluate the benefit of increased intravenous hydration in labor, as well as the role of supplemental oral hydration.

\section{References}

[1] Millen, K. R., Kuo, K., Zhao, L., \& Gecsi, K., (2014): Evidence-based guidelines in labor management. Obstetric Gynecol Surv 69: 209-17.

[2] Sandall, J., Soltani, H., Gates, S., Shennan, A., \& Devane, D., (2013): Midwife-led versus other models of care for childbearing women. Cochrane Database Syst Rev; (12): CD004667.

[3] Lavender, T., Hart, A., \& Smyth, R. M., (2013): Effect of partogram use on outcomes for women in spontaneous labour at term. Cochrane Database Syst Rev; (7): CD005461.

[4] Brown, H. C., Paranjothy, S., Dowswell, T., \&Thomas, J., (2013): Package of care for active management in labour for reducing caesarean section rates in low-risk women. Cochrane Database Syst Rev. (9):CD004907.

[5] Alfirevic, Z., Devane, D., \& Gyte, G. M. L., (2013): Continuous cardiotocography (CTG) as a form of electronic fetal monitoring (EFM) for fetal assessment during labour. Cochrane Database of Syst Rev, (5): CD006066.

[6] Toohill, J., Soong, B., \& Flenady, V., (2012): Interventions for ketosis during labour. Cochrane Database Syst Rev, (2): CD004230.

[7] Hodnett, E., Lowe, N., Hannah, M., William, A., \& Stevens, B., (2014): Effectiveness of nurses as providers of labor support in North American Hospitals, a randomized controlled trial. J, of the American association, 288 (11): 1373-81. 
[8] Devane, D., Lalor, J. G., Daly, S., McGuire, W., \& Smith, V., (2012): Cardiotocography versus intermittent auscultation of fetal heart on admission to labour ward for assessment of fetal wellbeing. Cochrane Database Syst Rev. (2): CD005122.

[9] Smyth, R. M., Alldred, S. K., Markham, C., (2013): Amniotomy for shortening spontaneous labour. Cochrane Database Syst Rev, (6): CD006167.

[10] Rezk, A., Abdel Razek, M., Abdel Karem, M., \& Eid, N. (2010): Does Hydration Shorten the Duration of Labour? The Department of Obstetrics \& Gynaecology, Faculty of Medicine, Benha University. Med. J. Cairo Univ., Vol. 78, No. 2, September: 13-17.

[11] Helwan hospital statistical centers (2012): Annual records of obstetric department.

[12] WHO, (1994): Preventing Prolonged labor: A practical Guide (the Partograph Par1: Principles and Strategies). Geneva.

[13] Apgar, V., (1953): A proposal for a new method of evaluation of the newborn infant. Curr Res Anesth Analg., 32 (4): 260267.
[14] Kavitha, A., Chacko, K. P., \&Thomas, E., (2012): A randomized controlled trial to study the effect of IV hydration on the duration of labor in nulliparous women Archives of Gynecology and Obstetrics, Volume 285, Issue 2, pp 343-346.

[15] Eslamian, R., Marsoose, V., \& Parkneeyat, Y., (2011): Increase intra venous fluid intake and the course of labour in nulliparous women. Int J Gynaecol Obs; 93: 102.

[16] Direkvan, D., Moghadam, A., \& Rezaeian, M., (2012): Increased Intravenous hydration of nulliparas in labor. International Journal of Gynecology and Obstetrics, 118 (3): 213-5.

[17] GARITE, T. J., WEEKS, J., \& PETERS-PHAIR, K., (2000): A randomized controlled trial of the effect of increased intravenous hydration on the course of labor in nulliparous women. Am. J. Obstet. Gynecol., 183 (6): 1544-8.

[18] Coc, A., Derksen-Schrock, A., \& Coco, K., (2010): A randomized Trial of increased intravenous hydration in labor when oral fluid is unrestricted. Fam Med 42 (1):52-56. 